for reproduction is not possible. This cannot be regarded as equivalent to rejuvenescence, since rejuvenescence is a process necessary for the maintenance of reproduction, and ought to occur periodically entirely iadependently of external conditions, whilst according to the above view conjugation originally only presented itself under unfavourable conditions of life and helped the species to surmount them.

Amongst the higher Protozoa the original import of conjugation seems already to have dropped into the background, as shown in the change in the nature of the process itself. The higher Infusoria are only temporarily fused with one another in conjugation, and it appears possible, and even probable, that the process has here already attained the full significance of sexual reproduction, and is to be regarded as functional as a source of variability only.

Amphigonic reproduction, having existed through countless generations of Protozoa in the form of conjugation, passed over to the Metazoa, and, though its original physiological effect lost importance or retired altogether into the background, was preserved from extinction and firmly retained because of the immeasurable advantages which are conferred by it in endowing the species with the power of adapting itself to new conditions of existence. The formation of new species which was possible amongst the lower Protozoa even without amphigony, amongst the Metazoa and Metaphyta was to be attained only by that process.

Amphigony has been lost in certain cases, either partially, as in the case of some lower Crustacea amongst which parthenogenetic generations alternate with sexual, or entirely, as in the case of certain gall-insects and plant-lice amongst which parthenogenesis has become the only form of reproduction. Such restriction to parthenogenetic reproduction may act so as to secure the existence of a species for a time, but according to the views as to the origin of hereditary variability here maintained, such a species dependent on parthenogenesis alone for reproduction must be near its period of dying out, as unable to adapt itself to any new conditions of existence which may arise, since in the loss of amphigonic reproduction it has lost the capability of mingling and increasing the individual hereditable peculiarities which occur amongst its members.

This conclusion is supported by the fact that no whole groups or genera occur the species of which are entirely parthenogenetic in their reproduction.

The persistence of functionless organs in species which are reproduced parth nogenetically is a further corroboration of the genera view as to the import of amphigonic reproduction here maintained. Since acquired peculiarities are not inherited, organs which fall out of use cannot become vestiges in a direct way, as has been hitherto assumed to be the case. The functionless organ becomes indeed weaker and less fully developed in the individual which does not use it, but this reduction in the organ is not transmitted to the offspring.

The explanation of the undoubted fact that such organs do become vestiges must be sought elsewhere. In order that any particular part of the body in any species may be maintained at the height of its functions, all individuals which possess this part in less completely perfect development must be excluded fron participation in the act of reproduction by perishing in the struggle for existence. As soon, however, as an organ ceases to be useful, this uninterrupted selection of the individuals with the best organs for the purpose of reproduction ceases also, and a con dition arises which the author terms " panmixia." Now not only the individuals with the best organs participate in reproduction, but also those with inferior ones. A mixture of all kinds of gradations in goodness and badness in the organ must be the inevitable result, and thus in the course of time a universal deterioration in the organ must be produced. The remarkable fact that the gradual disappearance of functionless organs is extremely slow appears much more in keeping with the above views as to the nature of the process than with those hitherto adopted. The effect of disease of an organ in the course of a single life is a very well marked one, and if it were transmissible even to a reduced extent direct to the offspring, the organ must become reduced to a minimum even in a hundred generations. Yet how many million generations must have elapsed since the whalebone whale abandoned the use of its teeth?

If this new view of the cause of the reduction of disused organs is assumed as correct, it follows that vestiges of organs can occur only amongst species with amphigonic reproduction, not amongst those with parthenogenetic reproduction only, and this appears to be the case. Superfluous organs do not become rudimentary in species parthenogenetically reproduced. As far as the author's investigations extend, the receptaculum seminis does not become aborted in such species, although it is entirely without function. Thus in Chermes, which is without males, the receptaculum seminis is present in the females unchanged; whilst, on the other hand, in Aphis, another plant-louse in which amphigonic reproduction is not extinct, but alternates regularly with parthenogenesis, the receptaculum seminis has become lost in the summer female.

These evidences in favour of the general views here expressed form, of course, no absolute proof of their correctness, but only give evidence in favour of their probability. Further evidence cannot be offered at present, the phenomena dealt with being extremely complicated and their explanation being such as can only be approached gradually.

The author, however, considers that he has plainly shown that the selection theory is by no means incompatible with the conception of the "continuity of the germ-plasma," and further, that as soon as this conception is accepted as correct sexual reproduction appears in an entirely new light, displays a reason for its existence, and becomes to a certain extent comprehensible.

H. N. MOSElEY

N.B. A criticism of Prof. Weismann's above theories by Prof. von Kolliker appears in the Zeitschrift fiir Wissenschaftliche Zoolugie, in the October part just issued.

\section{THE FUNCTION OF A UNIVERSITY ${ }^{1}$}

I GRATEFULLY accept the honour with which I have been invested thus publicly, and with such kindly feeling. In the future, as in the past, I shall give you my best endeavours.

By a fortunate accident it has happened that I am not called upon to speak to you on behalf of the University of California before I know somewhat of it. The six months which have elapsed since I entered upon the duties of the high office which I now hold, I have utilised in studying with minute care the University in its main features and in some of its details. This is not the place nor the time to speak of minor matters. It is, however, the very place and the very time for me to say to this audience that no friend of the University has any cause to fear, so long as all of us, Regents, Professors, and students alike, remain united in the future, as we are at this present moment, in a single effort toward the same high ends.

For nearly a hundred years the American Republic lived, and grew, and prospered, and the community of nations hardly knew her, and barely gave her place. So, on a smaller scale, it has been in California. The University here has lived, and grown, and prospered, and the communities outside of our own small circle hardly know us, and grant us our place reluctantly. It is a perfectly safe prediction that within the next twenty years, possibly within the next ten, the State of California will find suddenly that here in her midst she has a force on which she never reckoned-a reserve on which she never counted.

It is easy to see what advantages would come if this conviction were now wide-spread and firmly held. It is easy to seek feverishly to make ourselves quickly known, in order that we may be more widely useful. But, I am more and more convinced that if we are always ready, like a strong man, our opportunity will be here almost before we realise it.

Vital Points and Fundamental Principles. - What, then, are the aims upon which our eyes must be ever fixed, and toward which our energies must be ever directed? I will not name them all, nor count them over one by one. But I think that I can point out certain vital points that must be guarded ; certain principles that must be fundamental. Let us consider the demands which the community makes of the University, and again, the standards which the University should set for its individual members.

In the first place we must carefully examine what it is that we, as citizens, demand from the University. We must see to it that what we demand is consonant with what we ought to demand. If we find that we disagree with what seems to us to be the position of the University, ought we not in fairness to calmly inquire which of the two is right? Is there not at least a certain presumption that the efforts of a body of intelligent scholars cannot be all misdirected? The usual and careless way of meeting this question, even on the part of those who count ${ }^{\mathrm{I}}$ Inatagural Address by President Holden at the University of California. 
themselves firm friends of the University, is to pass over these differences of opinion lightly, and to lay them to the errors of the intelligent scholars themselves. "What does a college professor know about life?" we say; "he knows his speciality, his mathematics, his political economy, his physics. Let him keep to that and we are satisfied. But let us, who are engaged in the practical business of life, judge of life and its needs."

We, the faculties of the University, might admit this provisionally and for the sake of peace, and inside our web here at Berkeley go on spinning our theories and trusting to their truth for their commanding influence in the future of the State. We will do that most certainly, and if the theories are right they will prevail. If they are wrong we shall be brought to confusion.

The University Useful and Practical.-But we claim more than this. We claim that the University is one of the most useful, and in a high sense practical parts of the machinery of the State. It has a function as important, or more important than any other. It shares this function with the Church, and the voices of both are to be your guide. The chief and highest function of the University is to assert and perpetually prove to you that general principles-laws-govern man, society, nature, life, and to make unending war on the reign of temporary expedients.

Think how fundamental is this use of the University. Think in how many ways we accomplish it. In the lecture-room, in the laboratories, in the machine-shop, we bring the student face to face with history, with nature, with fixed qualities. In history, in philosophy, in politics, in physics, we see that definite causes produce their definite and inevitable results. In the laboratories we find that nature, candidly interrogated, gives unambiguous answers; that mathematical prediction,- the modern prophecy -is inevitably fulfilled in experiment. In the machine-shop we learn that the hard results in brass and iron will not lie, but that they point relentlessly to careless, shiftless errors, if they exist, or testify to faithful, honest, laborious work if it has been done.

General Principles against Temporary Expedients.-There is no day and there is no hour of the student's life that he is not brought face to face with results, and taught to see that these How from principles of universal application. Just in so far as a teacher can bring forth this great truth is he a successful teacher. Just in so far as a graduate has learned it, is the work of the University priceless to him. Just in so far as our professors and our students alike go forth into society and proclaim and prove the unending reign of general principles and the utter folly of putting temporary expedients in their place, is the University of prime value and use to the State. There was never a period or a country in which the reign of fundamental law needed more constant assertion and more perpetual proof than in our own period and our own country. All our modern inventions which give quick locomotion and quick transmission of thought tend to exalt the temporary expedient and to debase the general principle. The merchant of old time sent his ships to the Indies with their orders for two years or more; the diplomatist in a foreign country was separated by weeks or months from instructions by the Foreign Office. Now it requires but an hour to reach the uttermost parts of the earth. We have cable despatches which recount the doings of the King of Dahomey. the merchant changes his orders in Bombay as he reads the morning paper; the Secretary of State arranges the affairs of 'Tuesday on the afternoon of Monday.

The immediate and harmless effect of all this is to paralyse continuous effort based on sound belief, and to substitute a wavering policy of daily temporising. But the living danger is that society may come to permanently distrast the reign of laws. Recollect that we have to train our young men to appreciate this vital truth in the midst of a society where there are apparently many glaring exceptions to the rule ; in a society where wealth has come, it seems by accident, and where power seems not to have been gained by work. And when you remember this, remember also how deep and profound your gratitude should be to any institution which is by its traditions and its very nature devoted to the incessant announcement and to the perpetual proof of the fundamental truth of all life here and hereafter, namely, that it is governed by unchanging principles which cannot be evaded nor shirked, and that a national or a personal life built on the expedients of the day, like a house built on the sand, will inevitably come to ruin. When this truth is grasped and firmly builded into the character, then it is that the steam. engine and the telegraph and all the myriad inventions of the day first become truly useful. The man who can command them aright has his powers doubled and trebled. It is the highest use of the University to train such men.

President Gilman's Test of a University. - You must not for one-moment forget that the power of a university lies in its men. In its governors, its professors, and in its students. If you come here to our beautiful grounds and see them fair as they are today and always, if you see fine buildings and many of them, if you find our laboratories stocked with costly apparatus and our libraries with splendid books, you must not for that reason suppose you have a university fitted to the needs of the State. You are to inquire about far other things. And it is of prime importance that every citizen should know exactly what questions to ask. Nowhere have these questions been more eloquently or more pregnantly put than in a splendid address recently delivered by our former President, Dr. Gilman, at the noble University over which he now presides: "Remembering that a university is the best organisation for the liberal education of individuals and the best organisation for the advancement of science, apply the double test-what is done for personal instruction, and what is done for the promotion of knowledge?-and you will be able to judge any institution which assumes this name.

"Ask, first, is it a place of sound education? Are the youth who are trained within its walls honest lovers of the truth? Are they learned, are they ready, are they trustworthy? When they leave the academic classes do they soon find a demand for their services? Do they rise in professional life? Are they sought for as teachers? Do they show aptitude for mercantile, administrative, or editorial life? Do they acquit themselves with credit in the public service? Do the books they write find publishers? Do they win repute among those who have added to the sum of human knowledge? Have they the power of enjoy. ing literature, music, art ? Can they apply the lessons of history to the problems of our day? Are they always eager to enlarge their knowledge? Do they become constrvative members of society, seeking for progress by steady improvements rather than by the powers of destruction and death? Aregthey useful, courteous, co-operative citizens in all the relations of life? Do the charities, the churches, the schools, the public affairs of the community receive their constant consideration? Are there frequent manifestations among them of unusual ability in science, in literature, in oratory, in administration? As the roll of the alumni increases, and the graduates are counted by hundreds and not by scores, does it appear that a large proportion are men of honourable, faithful, learned, and public-spirited character? These are the questions by which, as the years go on, a university is to be tested; or, to sum up all questions in one, Is it proved to be a place for the development of manliness?"

It is to be noticed that the stress is laid upon one chief thingmanliness-and that two main questions are to be asked. What does the University do for personal instruction? and what does it do for the promotion of knowledge?

The answers to these questions will depend in every case upon the men whom the University has chosen as its teachers. It will depend not only on their intellectual attainments, but upon their personal characters. It is a most fortunate thing that the following out of a life of true devotion to learning brings, in so vast a majority of cases, the excellences and beauties of character which we desire and look for. We can all point to eminent examples of this in our midst-and it is so everywhere. We should see in a true University the true spirit of research kept alive and eagerly active. How ican you teaeh a young and ardent mind by means of examples culled from books alone? The vast panorama of nature lies before us, glorious by day, resplendent by night, and it is only from the actual pursuit of knowledge at first hand from nature itself that true teaching power is to be derived. Mere information can be gained from books and libraries. True knowledge must be attained by studies that develop mind and character at once.

The Genuine Issues of Life.-How, then, are we, the faculties of this University, to send forth from our midst men and women who are genuine, true, high, noble, sincere, simple? Men and women whose natures are such, and whose training has developed, harmonised and rounded out their natures? We must be constantly on the watch to put the genuine issues of life before ourselves and before our pupils. We are constantly tempted to put the name for the thing. How hard it is to avoid this even in our personal conduct, and how doubly hard it is in 
our public acts to point always to the essence, and not to indicate the accidents. We, all of us, suffer from the complexity of modern life which presents masses of detail, demanding attention, and distracting our imaginations with what seems to be but " a multitude of single instances." We lose the thread of logic and law and only grasp the tangled skein of various issues. We are prone to class quickly a man, an action, a belief, and have done with it and him. It seems to save our time. In reality it dissipates and degrades our life. Let $\mathrm{u}:$ take a familiar example. We meet a man for the first time. Our friend classifies him for us. He is introduced to us as a man of affairs, a physician, or a lawyer. We accept the crude classification based on what he does, and we forget the divine possibilities of what he $i s$ or may be. We indolently accept a commercial classifica-

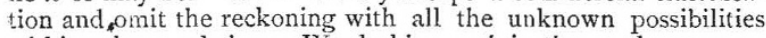
within a human being. We do him an injustice, and we go on to dull our own minds and sonls by repeated iterations of this stupid act until we become puppets meeting our like and not men meeting with our fellow-men. It is a lazy and a shiftless way, and unworthy of all of us. It inevitably dulls the mind by putting a word before a thought, a phrase before a principle, and this process ceaselessly repeated gradually eliminates all thought, and living men become mere dead automata in each other's eyes. Hardly any man is so dull that there are not possibilities unknown to you within him. To classify him at a glance and by a phrase is to deny the divine spark in him and a perceptive sense in your own heart. It is true that the higher a man's profession is the nearer should his life approach to the type signified by the name of that profession. It is safer to think you know mewhat of a poet when you hear that he is such than to predict the quality of a physician from his degree of doctor.

Complete Human Btings.-The University has no higher ideal than to train its students so that their practice may agree with their professions. But their complete professions are by no means signified by the formal degrees with which we invest them.

We grant the degree of A.B. to successful candidates. But A.B. does not really stand for what we have tried to teach. What we wish to teach our students and ourselves is to be complete human beings. Nothing less than this. There can be nothing more. We wish them to be H.B.'s first-human beings-and A.B.'s afterwards. Let any one of us try to see what is meant by a deserved title such as this. What is a human being con lete in every way? Is there a manly virtue, is there a ferninine grace, is there a divine aspiration which we can conceive to be lacking to such a personality? How carelessly we use the phrase, and with what debased significance! Is the man who has sacrificed his very nature to the service of money deserving of the title? Is it any better if power be the thing he has sold his birthright for? or vanity? or pleasure? or fame?

The moment we reflect upon the inner senses and upon the connoted meaning of the word, we see how we have debased it. We are used to lift a beggar from the ditch and to say with a pity that is half repulsion --at least he is a human being. Bu when we reflect we see that we can give no higher praise than this to the men who are the chiefest glories of the race. 'Think of David, King of Israel. How can we praise him, appreciate him, feel his power over us at this day, better than to recognise that he was a complete being human in every part? That is allied directly with Divinity. St. Peter, Socrates, the great Emperor Marcus Aurelius-these touch us through a chord of complete unison of their human natures with ours. What is it that is common to the great Alfred of England and to the poet who sang the beauties of the daisy overturned by the plough ? What but this human nature that embraces our own and harmonises with its every part?

In America, young as we are, we have had our complete human beings. We can point to the oration at Gettysberg and know that the man who wrote it did so out of the fulness of a complete human nature. The soldier whose forces were overcome on that fearful field will live in history by his martial deeds, but he will be cherished in our hearts for the rounded symmetry of his humanity. In fiction we have all given this high degree. Where can we find more perfect examples than Col. Newcome or Henry Esmond? Is it not worth reflection to see why it is that these stand for us as types of what a man can become ?

I think we can conceive of what our ideal of a human being should be by seeking to find the common quality of men so re- moved from each other in character and circumstance as King David, Peter the A postle, Socrates, Alfred, Burns, Lincoln, Lee. The great Marcus has even defined such a man for us in formal words: he is "a man who delays $n$ t to be among the best, like a priest and minister of the gods ; who uses the deity planted within him, which makes him uncontaminated by pleasure, unharmed by pain, untouched by insult, a fighter in the noblest fight, not overpowered by any passion, deep-dyed with justice, and accepting with his soul all that happens and is his portion."

It must be our aim and end to fix clearly in the mind of every pupil that the whole object of his college course should be one and the same as the whole object of his entire life, namely, to be a real human being. Not to strive for partial knowledge, for partial facts as an end, and finally to be graduated a Bachelor of Arts, but to strive for complete and utter manhood and to add to its magnificent qualities all the learning which our schools afford simply as a help towards carrying out his inmost and his highest aspirations. Each one of us should be ever striving to deserve among our fellows and in our most secret life this chief of all titles. The one that expresses the sum of all achievement possible to us; since when it is attained it fixes us as wholly human, and thus made in the image of divinity. The best title of our Master was the Son of Man, and $\mathrm{He}$ descended to this to show the term to which we might attain.

$A$ Word to the Graduates,-And now, members of the graduating class, I wish to say one parting word especially to you, who are soon to see the formal signs of the approval of your professors and of our governors--the Regents.

In the name of the University I welcome you to your new estate. If we have done our duty by you, you are equipped for the beginning of your maturer life. If you do your duty by yourselves and by society there is nothing which you need fear to undertake. Here, on the very borders of the most western sea, in a golden land of promise, let me repeat to you the noble words which were first written down eighteen hundred years ago, in the midst of a savage wilderness, in the presence of hostile barbarians, by the hand of the greatest and most virtuous of the rulers of imperial Rome, sitting alone and silent in his soldier's tent. Let these great sentences be at once our farewel and our God-speed to each one of you :-

"If thou workest at that which is before thee, following right, reason calmly, vigorously, allowing nothing to distract thee, but keeping thy divine part pure, although bound to give it back immediately-if thou holdest to this, expecting nothing and fearing nothing, with heroic truth in every word and sound which thou utterest, then thou wilt live happy-and there is no man able to prevent thee."

\section{ANTARCTIC EXPLORATION}

THE author began by referring to the results established by Gauss in 1839 . Gauss proved: "(I) That the knowledge of $\mathrm{Y}$ (the west component of the horizontal component of terrestrial magnetism, called usually $\mathrm{X}$ ) over the whole earth, along with the knowledge of $\mathrm{H}$ (the north component of $\mathrm{H}$ ) at all points on a line running from one pole to the other, is sufficient for the foundation of a comflete theory of the magnetism of the earth. (2) That a finally complete theory was also deducible from the simple knowledge of $Z$ (the component of the earth's magnetism, that is directed to the earth's centre) on the whole earth's surface." There existed, for a large part of the earth's surface, data for large charts of the normal values of the declination of $\mathrm{H}$ and of $\mathrm{Z}$, at the epoch 1880 , from which $\mathrm{X}, \mathrm{Y}$, and $Z$ could readily be deduced. These charts were accurate for the zone lying between $60^{\circ} \mathrm{N}$. and $50^{\circ} \mathrm{S}$. lat. (except for some parts of North Asia and of Central Africa); they were less accurate for $60^{\circ}$ to $70^{\circ} \mathrm{N}$. lat, and $50^{\circ}$ to $60^{\circ} \mathrm{S}$. Beyond these limits in the south, lay regions almost unvisited since Ross's Expedition in I840-43; so that the charts were correspondingly weak in those latitudes. The charts show that the Challenger crossed the Antarctic Circle about the meridian $79^{\circ} \mathrm{E}$. These and other somewhat recent observations made between $50^{\circ}$ and $60^{\circ} \mathrm{S}$. lat., show that considerable changes in the magnetic elements have occurred since Ross's time, and therefore the charts for 1880 cannot be com$x$ "On the Advantages to the Science of Terrestrial Magnetism to be obtained from an Expedition to the Region within the Antarctic Circle." Abstract of a paper read at the Birmingham meeting of the British Associa tion by Capt. Ettrick W. Creak, R. N., F.R.S. 